Maciej Bieliński ${ }^{1,2}$, Bogdan Mietła², Alicja Popiołek², Aleksandra Chyrek-Tomaszewska², Grzegorz Pulkowski², Jacek Budzyński ${ }^{2,3}$ and Alina Borkowska ${ }^{1}$

${ }^{1}$ Chair and Department of Clinical Neuropsychology, Nicolaus Copernicus University in Toruń, Collegium Medicum in Bydgoszcz, Poland

${ }^{2}$ Clinic of Vascular and Internal Diseases, Jan Biziel University Hospital No. 2, Bydgoszcz, Poland

${ }^{3}$ Chair of Vascular and Internal Diseases, Nicolaus Copernicus University in Toruń, Collegium Medicum, Bydgoszcz, Poland

\title{
Evaluation of clinical and psychological parameters in subgroups of people with paroxysmal, persistent, and long- standing persistent atrial fibrillation
}

\author{
Corresponding author: \\ Maciej Bieliński PhD \\ Chair and Department \\ of Clinical Neuropsychology, \\ Nicolaus Copernicus University \\ in Toruń, \\ Collegium Medicum in Bydgoszcz \\ ul. Marii Curie-Skłodowskiej 9 , \\ 85-094 Bydgoszcz, Poland \\ E-mail: bielinskim@gmail.com
}

Medical Research Journal 2017; Volume 2, Number 4, 157-164 10.5603/MRJ.2017.0022 Copyright (C) 2017 Via Medica ISSN 2451-2591

\begin{abstract}
Background. Atrial fibrillation (AF) may cause worsening of haemodynamic function of the heart, occurrence of peripheral embolism, emotional disorders, and secondary occurrence of cognitive deterioration. It seems that patients with AF constitute a heterogeneous group in terms of features characterising both the arrhythmia itself and their psychophysical efficiency. Taking this into account, the aim of the work was to assess the psychophysical condition of patients with various forms of AF.

Methods. The study included 80 subjects diagnosed with AF. Patients underwent a clinical and neuropsychological evaluation, including clinical interview and physical examination, biochemical and echocardiographic parameters, physical performance (6MWT), cognitive and executive functions (TMT A and B, Stroop 1 and 2, RAVLT), and severity of depressive symptoms (BDI).

Results. Analysis of the results of neuropsychological tests revealed significantly worse performance of TMT B and RAVLT A3 by patients with long-standing persistent AF than among patients with non-permanent AF. The subjects with long-standing persistent arrhythmia also walked a significantly shorter distance in $6 \mathrm{MWT}$. In $55 \%$ of subjects, clinically significant depressive symptoms were observed. However, there were no significant differences in the values of echocardiographic parameters between particular groups. Conclusions. Long-standing persistent type of AF was associated with worse results of psychophysical efficiency, and exercise performance, likewise in cognitive and executive functioning. More than half of patients with AF presented features of depressive disorders.

Keywords: atrial fibrillation, cognitive functioning, depressive symptoms
\end{abstract}

Med Res J 2017; 2 (4): 157-164

\section{Introduction}

Atrial fibrillation (AF) is, along with heart failure, one of the most common disease entities among patients with cardiovascular disease. Its prevalence is estimated at $1-2 \%$ of the general population, and the risk of AF increases with age. It is estimated that in the world, this arrhythmia affects about 30 million people and in 6-26\% can be complicated by ischaemic stroke, which is characterised by worse course than ischaemic strokes on another medium [1-4]. Atrial fibrillation is associated with an increased percentage of total deaths, sudden deaths, strokes, and other thromboembolic events. It leads to the development of heart failure, increases the probability of hospitalisation, and reduces the quality of life, and physical and intellectual efficiency $[1,3]$.

The occurrence of atrial fibrillation can influence the function of the circulatory system and nervous system, and psychophysical functioning of patients on different ways. It may affect haemodynamic parameters or may cause occurrence of peripheral embolism and emotional disturbances $[1,3,5]$.

Impaired cardiac and haemodynamic functions may be manifested as a reduction in exercise tolerance as well as organ ischaemia, especially the brain, which is particularly sensitive to oxygen deficiency. It is estimated that hypoperfusion of the central nervous system 
(CNS) associated with, among others, arrhythmias may lead to the development of vascular dementia $(\mathrm{VaD})$, but also may be important in Alzheimer's dementia (Alzheimer's disease - AD) [6-7]. Several studies have shown that chronically low blood pressure values and reduced cardiac output result in reduced cerebral perfusion and CNS activity assessed by the local functioning of the neocortex [8].

Peripheral embolism in the course of AF in $70-90 \%$ of cases concerns the cerebral arteries. It can be of varied intensity and present in a wide range of neurological syndromes, from mute clinically to extensive strokes, both ischaemic, due to congestion and haemorrhage, as a complication of anticoagulant therapy. However, it is believed that even embolism that does not cause clinically evident symptoms may eventually lead to dementia or less explicit cognitive and characterological alteration. The occurrence of asymptomatic, clinically silent strokes, which are found in neuroimaging studies, more than doubles the risk of dementia [9-11].

Atrial fibrillation can also induce emotional and mental disorders (depression, anxiety), associated with a threat to life, job loss (frequent hospitalisations), and the need to take medication. The literature described the observations that the severity of depressive symptoms in patients with AF is higher than in the healthy population [12-13]. There are also reports suggesting that the higher severity of depressive disorders intensifies the patient's feelings related to the occurrence or persistence of atrial fibrillation, which may worsen the quality of life [14]. This is an important aspect indicating the importance of assessing the affective functioning of patients with the most prevalent arrhythmia.

The essence of haemodynamic and embolic-thrombotic consequences of atrial fibrillation suggest that this is an arrhythmia that can cause significant cognitive deterioration. What is more, in observational studies, the frequency of AF in the population of people with dementia was significantly higher than in people without cognitive impairment [9]. However, there is no convincing evidence in the literature about the direct relationship between AF and cognitive impairment, and no specific neuropsychological dysfunction has been diagnosed in patients with AF. However, the assessment of the degree of cognitive functions in this group of patients is of great importance, for example due to the need for constant treatment with potentially life-threatening side effects. In the case of anticoagulant therapy, the tragic consequence for the patient may be both the failure to take the drug and its overdose. In view of the prolonged average life time and associated aging population, the problem of AF and its complications is becoming increasingly current and important. The presented work put emphasis on the assessment of psychophysical efficiency, which on the one hand shapes the quality of life of patients, and on the other determines their ability to live independently. It seems that patients with atrial fibrillation constitute a heterogeneous group in terms of features characterising both the arrhythmia itself and their psychophysical efficiency.

Based on the above, the aim of the work was to assess the psychophysical condition of patients with various forms of atrial fibrillation. The paper includes assessment of clinical, biochemical, and echocardiographic parameters as well as physical performance, cognitive functions, and severity of depressive symptoms. Another aim of the study was to assess possible relationships between clinical (echocardiographic and biochemical) markers of cardiovascular status and psychophysical functioning patients with different duration of atrial fibrillation.

\section{Materials and methods}

The study included 80 patients hospitalised in the Clinic of Vessel and Internal Diseases of University Hospital No. 2 in Bydgoszcz with the diagnosis of atrial fibrillation, who expressed their willingness to participate in the project by signing an appropriate statement. It included 31 women and 49 men, of Polish nationality, Caucasian, aged 45-84 (average age 66.1 \pm 8.3) years. The following inclusion criteria were adopted: non-valvular atrial fibrillation diagnosed according to standard criteria [1], ability to perform a six-minute walking test, ability to understand the purpose of the examination, lack of incapacitation, and patient's informed consent to participate in the study. While the exclusion criteria were: significant heart failure or heart valve surgery, dementia, diagnosed mental illness, symptomatic stroke, serious somatic, psychiatric, or neurological disorder, or addiction, and lack of ability to perform a walking test.

All patients were subjected to medical and neuropsychological assessment. The assessed medical parameters include demographic and clinical aspects (e.g. duration of AF, co-morbidities, medication, anthropometric parameters), biochemical parameters, transthoracic echocardiography, electrocardiographic evaluation, exercise capacity assessment in the six-minute walk test (6MWT), and neuropsychological assessment including cognitive function and the severity of depressive symptoms. The neuropsychological examination was carried out by three adequately trained people in a quiet, secluded room using the Rey Auditory Verbal Learning Test (RAVLT), Stroop Test in the original version, and the Trial Making Test parts A and B (TMT). The Beck Depression Inventory (BDI) was used to assess the severity of depressive symptoms. The statistical analysis was performed using the licensed version of STATISTICA 12.5 for the Windows operating system (StatSoft). The distribution of variables was checked 
Table 1. Basic demographic, clinical, echocardiographic, and biochemical parameters in subgroups for different duration of $\mathrm{AF}$

\begin{tabular}{|c|c|c|c|c|}
\hline Parameter & $\begin{array}{c}A F<48 h \\
(n=34 ; 42.5 \%)\end{array}$ & $\begin{array}{c}\text { AF }>48 h \\
(n=27 ; 33.75 \%)\end{array}$ & $\begin{array}{c}\text { Permanent AF } \\
(n=19 ; 23.75 \%)\end{array}$ & $\mathbf{p}$ \\
\hline Age $(y)$ & $67.5 \pm 47.0-79.0$ & $66 \pm 58-69$ & $69.0 \pm 55.0-84.0$ & 0.27 \\
\hline Gender ( $+, \hat{n} \mathrm{n}, \%)$ & $\begin{array}{l}11(32.5 \%) \\
23(67.5 \%)\end{array}$ & $\begin{array}{l}10(37 \%) \\
17(63 \%)\end{array}$ & $\begin{array}{c}10(52.5 \%) \\
9(47.5 \%)\end{array}$ & 0.34 \\
\hline Diabetes (n, \%) & $5(14.7 \%)$ & $8(29.6 \%)$ & $8(42.5 \%)$ & 0.13 \\
\hline Hypertension (n, \%) & $21(61.8 \%)$ & $16(59.2 \%)$ & $14(73.6 \%)$ & 0.60 \\
\hline $\operatorname{IHD}(\mathrm{n}, \%)$ & $8(23.5 \%)$ & 7 (25.9\%) & $4(21 \%)$ & 0.88 \\
\hline BMI $\left(\mathrm{kg} / \mathrm{m}^{2}\right)$ & $28.5 \pm 24.2-37.9$ & $30.6 \pm 18.3-36.7$ & $28.8 \pm 22.8-43.1$ & 0.68 \\
\hline Echocardiography LV (mm) & $50 \pm 46-55$ & $49 \pm 45-52$ & $50.0 \pm 48.0-54.0$ & 0,43 \\
\hline $\mathrm{LA}(\mathrm{mm})$ & $45 \pm 44-48$ & $46 \pm 42-50$ & $47.0 \pm 45.0-51.0$ & 0,22 \\
\hline IVS (mm) & $12.0 \pm 11.0-14.0$ & $12 \pm 10-14$ & $11.0 \pm 10.0-13.0$ & 0,26 \\
\hline $\mathrm{PW}(\mathrm{mm})$ & $12.0 \pm 11.0-14.0$ & $11.5 \pm 10-14$ & $11.0 \pm 10.0-13.0$ & 0,45 \\
\hline LVEF (\%) & $60.0 \pm 55.0-68.0$ & $60 \pm 60-70$ & $60.0 \pm 50.0-60.0$ & 0,06 \\
\hline TRH (mU/l) & $0.9 \pm 0.5-1.24$ & $1 \pm 0.9-1.44$ & $0.9 \pm 0.5-1.2$ & 0.61 \\
\hline Creatinine (mg/dl) & $1 \pm 0.9-1.3$ & $1.1 \pm 0.95-1.3$ & $1 \pm 0.9-1.3$ & 0.77 \\
\hline CRP (mg/dl) & $1.7 \pm 0.86-3$ & $2.1 \pm 1-3.8$ & $3.5 \pm 2.9-4.2$ & 0.27 \\
\hline TC (mg/dl) & $175 \pm 148-206$ & $170 \pm 142-211.5$ & $175 \pm 150-203$ & 0.66 \\
\hline HDL-C (mg/dl) & $46 \pm 37-65$ & $42.5 \pm 35-54$ & $43 \pm 41-48$ & 0.63 \\
\hline LDL-C (mg/dl) & $111 \pm 92-120$ & $111 \pm 85-135$ & $105 \pm 92-123$ & 0.81 \\
\hline TG (mg/dl) & $139.5 \pm 112-184$ & $119 \pm 62-199$ & $141.5 \pm 94-179$ & 0.81 \\
\hline Glucose (mg/dl) & $101 \pm 92-112$ & $99 \pm 84.5-106$ & $96 \pm 86-107$ & 0.63 \\
\hline
\end{tabular}

Data are shown as median $\pm 25^{\text {th }}-75^{\text {th }}$ quartile. The significance of differences between groups was assessed using Kruskal-Willis' ANOVA test. BMI- body mass index, IHD - ischaemic heart disease, LV-left ventricle, LA-left atrium, IVS - interventricular septum, PW - posteriori wall, LVEF - left ventricle ejection fraction, TRH - thyrotropin releasing hormone, CRP - C-reactive protein. TC - total cholesterol, HDL-C - high-density lipoprotein cholesterol, LDL-C - low-density lipoprotein cholesterol, TG — triglycerides

using the Shapiro Wilk test. To assess the significance of differences in quantitative variables between groups of patients, the U-Mann-Whitney test or the Kruskal-Wallis ANOVA test were used (for significant differences, post-hoc analysis was performed with NIR Fischer tests or with the Bonferoni test). The analysed variables did not meet the criterion of normal distribution, hence the results were presented in the form of the median and the $25^{\text {th }}$ and $75^{\text {th }}$ quartiles.

The study was approved by the Bioethics Commission at Collegium Medicum of the Nicolaus Copernicus University in Bydgoszcz, No. KB 124/2006 (Appendix No. 7) with later annexes (including from 17.12.2013 - Annex No. 8). The study was conducted in accordance with the revised Helsinki Declaration.

\section{Results}

For the purpose of this work, the study group was divided by the length of duration of AF into three subgroups: AF $<48$ hours, AF $>48$ hours, and permanent AF. Basic data on the size of sub-groups and demographic data are included in Table 1. The obtained results did not differ significantly in individual groups of patients. It was particularly interesting that in the range of echocardiographic results, the expected differences in the results of the left atrium size were not confirmed in the study group. Also, the thickness of the left ventricular muscle responsible for its pressure overload and the expression of its remodelling were not significantly different in the analysis. There were no significant relationships between echocardiographic parameters and the results of neuropsychological tests.

An important element of the study was the neuropsychological assessment of patients with AF, the results of which are shown in Table 2. Data revealed significant differences in TMT B and A3 RAVLT performance.

The 6-MWT was used to assess physical performance, and the results in individual groups are presented in Table 3. The shortest distance was achieved by patients from the group of permanent atrial fibrillation, although the results in the subgroups did not differ significantly. Then the 6MWT results were correlated with the results of neuropsychological tests (Table 
Table 2. Performance of TMT A and B, Stroop $A$ and $B$, RAVLT, and BDI tests in subgroups with different AF duration

\begin{tabular}{|c|c|c|c|}
\hline & $\begin{array}{c}A F<48 h \\
n=34\end{array}$ & $\begin{array}{c}A F>48 h \\
n=27\end{array}$ & $\begin{array}{c}\text { Permanent } \\
\text { AF } \\
n=19\end{array}$ \\
\hline TMT A & $\begin{array}{c}39.5 \\
33.0-52.0\end{array}$ & $\begin{array}{c}40.5 \\
30.0-59.0\end{array}$ & $\begin{array}{c}50.0 \\
42.0-60.0\end{array}$ \\
\hline TMT B & $\begin{array}{c}91.0 \\
(75.0-138.0)\end{array}$ & $\begin{array}{c}106.0 \\
(88.0-138.5)\end{array}$ & $\begin{array}{c}143.5^{\star} \\
114.0-168.0)\end{array}$ \\
\hline STROOP 1 & $\begin{array}{c}27.5 \\
25.0-35.0\end{array}$ & $\begin{array}{c}26.0 \\
24.0-31.0\end{array}$ & $\begin{array}{c}30.0 \\
24.0-36.0\end{array}$ \\
\hline STROOP 2 & $\begin{array}{c}86.5 \\
71.0-97.0\end{array}$ & $\begin{array}{c}80.0 \\
68.0-100.0\end{array}$ & $\begin{array}{c}83.5 \\
76.0-99.0\end{array}$ \\
\hline RAVLT A1 & $\begin{array}{l}5.0 \\
3.0-5.0\end{array}$ & $\begin{array}{c}4.0 \\
3.0-6.0\end{array}$ & $\begin{array}{c}5.0 \\
2.0-5.0\end{array}$ \\
\hline RAVLT A2 & $\begin{array}{l}7.0 \\
6.0-9.0\end{array}$ & $\begin{array}{c}7.0 \\
6.0-8.0\end{array}$ & $\begin{array}{c}8.0 \\
7.0-8.0\end{array}$ \\
\hline RAVLT A3 & $\begin{array}{c}10.0 \\
8.0-11.0\end{array}$ & $\begin{array}{c}8.0 \\
7.0-9.0\end{array}$ & $\begin{array}{l}7.0 * * \\
6.0-8.0\end{array}$ \\
\hline RAVLT A4 & $\begin{array}{c}11.0 \\
9.0-12.0\end{array}$ & $\begin{array}{c}10.0 \\
8.0-11.0\end{array}$ & $\begin{array}{c}10.0 \\
6.0-11.0\end{array}$ \\
\hline RAVLT A5 & $\begin{array}{c}11.0 \\
9.0-13.0\end{array}$ & $\begin{array}{c}11.0 \\
9.0-13.0\end{array}$ & $\begin{array}{c}11.0 \\
8.0-13.0\end{array}$ \\
\hline RAVLT B1 & $\begin{array}{c}4.0 \\
4.0-6.0\end{array}$ & $\begin{array}{c}5.0 \\
3.0-5.0\end{array}$ & $\begin{array}{c}4.0 \\
3.0-5.0\end{array}$ \\
\hline RAVLT A6 & $\begin{array}{c}9.0 \\
6.0-10 .\end{array}$ & $\begin{array}{c}8.0 \\
5.0-10.0\end{array}$ & $\begin{array}{c}8.0 \\
5.0-9.0\end{array}$ \\
\hline RAVLT A7 & $\begin{array}{c}9.0 \\
7.0-11.0\end{array}$ & $\begin{array}{c}8.5 \\
5.0-11.0\end{array}$ & $\begin{array}{c}6.5 \\
5.0-9.0\end{array}$ \\
\hline $\begin{array}{l}\text { RAVLT } \\
\text { Recognition }\end{array}$ & $\begin{array}{c}12.0 \\
9.0-15.0\end{array}$ & $\begin{array}{c}11.0 \\
10.0-14.0\end{array}$ & $\begin{array}{c}12.5 \\
11.5-13.0\end{array}$ \\
\hline BDI & $\begin{array}{c}11.0 \\
7.0-16.00\end{array}$ & $\begin{array}{c}14.0 \\
11.0-19.0\end{array}$ & $\begin{array}{c}12.0 \\
5.5-17.0\end{array}$ \\
\hline
\end{tabular}

Data are shown as median $\pm 25^{\text {th }}-75^{\text {th }}$ quartile. The significance of differences between groups was assessed using Kruskal-Willis' ANOVA test. * $-p=0.026$ Subsequent post hoc analysis did not reveal any significant differences between the different groups, although for the NIR Fischer test the difference between groups with $A F<48$ hours and fixed AF gave the result in the trend $(p=0.06) . ; * \star-p=0.019$ The results in the $\mathrm{A} 3$ range were significantly different for KruskalWallis ANOVA $p=0.019$. Post hoc analysis, for the Bonferoni test $p$ $=0.049$ for groups with $\mathrm{AF}<48 \mathrm{~h}$ and permanent AF.TMT A - Trail Making Test, A, RAVLT A1-A7, B1- Rey Auditory Verbal Learning Test; BDI - Beck Depression Inventory
5). The longer distance walked in the test correlated significantly with the better test results dependent of the prefrontal cortex.

The last analysis concerned the prevalence and severity of depressive symptoms in the study group (Table 5) and their correlation with the results of cognitive tests (Table 6). The highest intensity of depressive symptoms was found in the group of patients with AF > 48 hours; however, the differences did not reach statistical significance. However, significant correlations were found for the higher severity of depressive symptoms, which were associated with worse prefrontal cortex function and deferred memory.

\section{Discussion}

In the literature, there is evidence that patients with AF present a worse cognitive functioning than those in the general population, although it was not

Table 4. Spearman's rank correlations of the 6MWT result with the results of cognitive tests

\begin{tabular}{lcc}
\hline Parameter & R (z 6 MWT) & P \\
\hline TMT A & -0.3484 & 0.001 \\
TMT B & -0.2991 & 0.007 \\
RAVLT A1 & 0.3127 & 0.004 \\
RAVLT A2 & -0.0270 & 0.81 \\
RAVLT A3 & 0.1262 & 0.26 \\
RAVLT A4 & 0.0838 & 0.45 \\
RAVLT A5 & 0.0837 & 0.46 \\
RAVLT B1 & 0.0723 & 0.52 \\
RAVLT A6 & 0.1779 & 0.11 \\
RAVLT A7 & 0.0003 & 0.99 \\
RAVLT Recog & 0.1636 & 0.14 \\
STROOP 1 & -0.3210 & 0.0004 \\
STROOP 2 & -0.3883 & 0.0004 \\
BDI & -0.2412 & 0.03
\end{tabular}

Correlations relevant for $p<0.05 \mathrm{BDI}-$ Beck Depression Inventory, TMT A, B-Trail Making Test, part A and B; RAVLT A1-A7, B1- Rey Auditory Verbal Learning Test; Stroop test 1 and 2;

Table 3. 6MWT distance in patients with subgroups with different duration of AF

\begin{tabular}{lccc}
\hline $\mathbf{A F}<\mathbf{4 8 h}$ & $\mathbf{A F}>\mathbf{4 8 h}$ \\
$\mathbf{n}=\mathbf{3 4}$ & 307.5 & 327.5 & $\begin{array}{c}\text { Permanent AF } \\
\mathbf{n}=\mathbf{1 9}\end{array}$ \\
\hline 6 MWT $(\mathrm{m})$ & $265.0-350.0$ & $270.0-370.0$ & 290.0 \\
& & $250.0-380.0$
\end{tabular}

Data are shown as median $\pm 25^{\text {th }}-75^{\text {th }}$ quartile. No significant differences in Kruskal-Wallis's ANOVA test. 6MWT-6-minute walk test 
Table 5. BDI results in subgroups with varying duration of AF.

\begin{tabular}{cccc}
\hline & $\begin{array}{c}\mathrm{AF}<\mathbf{4 8 h} \\
\mathbf{n}=\mathbf{3 4}\end{array}$ & $\begin{array}{c}\mathrm{AF}>\mathbf{4 8 h} \\
\mathbf{n}=\mathbf{2 7}\end{array}$ & $\begin{array}{c}\text { Permanent AF } \\
\mathbf{n}=\mathbf{1 9}\end{array}$ \\
\hline $\mathrm{BDI}$ & 11.0 & 14.0 & 12.0 \\
& $7.0-16.00$ & $11.0-19.0$ & $5.5-17.0$ \\
\hline
\end{tabular}

Data are shown as median $\pm 25^{\text {th }}-75^{\text {th }}$ quartile. Differences not relevant to the Kruskal-Wallis ANOVA test; BDI - Beck Depression Inventory

Table 6. Spearman's rank correlation of BDI values with the results of neuropsychological tests

\begin{tabular}{lcc}
\hline Parametr & R (BDI) & P \\
\hline TMT A & 0.1927 & 0.08 \\
TMT B & $0.3886^{*}$ & 0.0003 \\
RAVLT A1 & -0.1927 & 0.08 \\
RAVLT A2 & -0.0568 & 0.62 \\
RAVLT A3 & -0.2071 & 0.06 \\
RAVLT A4 & -0.0717 & 0.52 \\
RAVLT A5 & -0.1282 & 0.25 \\
RAVLT B1 & -0.0325 & 0.77 \\
RAVLT A6 & -0.1981 & 0.07 \\
RAVLT A7 & -0.1980 & 0.07 \\
RAVLT Recog & $-0.3195^{\star}$ & 0.003 \\
STROOP 1 & $0.2298^{*}$ & 0.04 \\
STROOP 2 & $0.2235^{*}$ & 0.04
\end{tabular}

Significant differences for $\mathrm{P}<0.05$ TMT A, B-Trail Making Test parts A and B; RAVLT A1-A7, B1- Rey Auditory Verbal Learning Test; Stroop test 1 and 2 .

confirmed that it would be dependent on the duration of arrhythmia [15-17]. In the current study, the analysis of the results of neuropsychological tests obtained in individual subgroups of patients, divided according to the duration of $A F$, showed a significantly worse performance of part B of the Trial Making Test (TMT B) and attempt $\mathrm{A} 3$ of the auditory memory test (RAVLT A3) by patients with permanent atrial fibrillation (Table 2). This suggests the possibility of impaired functioning of the visual and spatial working memory in patients with more advanced atrial arrhythmia. In the other neuropsychological tests there was no significant differentiation between subgroups with particular types of arrhythmias (Table 2). Lack of differences in the performance of both parts of the Stroop test and part A of the Trial Making Test (TMT A) does not allow diagnosis of discrepancies in the existence of global working memory and executive function disorders, and thus prefrontal cortex dysfunction. Similarly, the results of the RAVLT do not show significant differences in short-term and delayed memory between subgroups of patients with different AF duration.

Another important element in assessing the psychophysical state of a patient with $\mathrm{AF}$ is the analysis of physical performance, which is considered as an indicator of haemodynamic consequences of arrhythmia. The study evaluated the differences in the results of a six-minute walking test in subgroups with different duration of arrhythmia. It turned out that the best results were obtained by patients with persistent atrial fibrillation (lasting $>48$ hours) and the worst with permanent (Table 3). Differences between individual groups were around $10 \%$ and did not gain statistical significance. Similar observations have been described in the literature [18-19]. There were also studies based on the assessment of physical performance in patients with atrial fibrillation before and after effective electrical cardioversion [20-21]. It was found, among other things, that effective and long-term restoration of the sinus rhythm results in a longer distance covered in the test. The beneficial effects of electrical cardioversion on cardiac performance parameters were also confirmed by other haemodynamic, clinical (NYHA), spirometric parameters and also by quality of life [18-22].

Regular physical activity is a recognised factor that improves cognitive functioning. The improvement of cognitive functions depending on regular aerobic exercise applies to healthy people in all age groups, but also to patients [23]. Regular aerobic training improves cognitive functioning in the aspect of attention and psychomotor speed, executive functions, and memory [23].

In the analysed group, there were clear, significant correlations of the distance travelled during 6MWT with the results of tests examining the prefrontal cortex activity (Table 4). The 6MWT distance significantly correlated with the better performance of both parts of the Stroop Test and the TMT. The positive correlation of GMWT with the number of repeated words in the A1 attempt of RAVLT was also significant. All these tests describe better performance in the area of working memory and executive functions [24]. Such an observation indicates a favourable relationship between physical performance and cognitive functioning in the study group. This assumption is confirmed in numerous publications concerning patients with various areas of somatic dysfunctions [25-27]. In the study group, there was also a significant negative correlation of the 6MWT distance with the Beck Depression Inventory (Table 4). Probably, such a result is associated with a higher quality of life of physically fit patients [28-30].

Among the patients of advanced age, physical fitness determines the degree of independence and allows the possibility of autonomous living. Undoubtedly, dependence on other people significantly reduces the level of life satisfaction and generates mood 
disorders. It turns out, however, that this effect has not been demonstrated in all publications investigating the correlation of physical fitness with the level of depressive disorders. For example, better physical performance did not correlate with the lower scores of scales assessing the severity of depressive disorders in patients with rheumatoid arthritis [31] or after a stroke [32]. However, in many studies on other medical conditions, it has been confirmed that better parameters of physical performance are associated with lower depression intensity [33-34].

The results obtained in the present study show the occurrence of significant depressive disorders measured by the BDI self-esteem scale in $55 \%$ of the study group, which is a much larger percentage than in the general population; in Polish conditions this prevalence is approximately $3 \%$ [35]. Such a result corresponding with other studies suggests that atrial fibrillation may be an important clinical factor predisposing to the occurrence of depressive disorders or vice versa. The information from available publications are mostly consistent and indicate a significantly higher level of depressive disorders among people with AF compared to the general population [36-37]. It was also shown that patients with AF present stronger symptoms of anxiety than patients with other supraventricular arrhythmias associated with the re-entry mechanism [38]. Nevertheless, there are also papers in the literature that do not confirm the greater severity of depression and anxiety in the group of patients with AF [39]. There are also discrepancies in the significance of depressive disorders in particular types of atrial fibrillation. In the present study, the highest level of depressive symptoms was observed in patients with persistent AF lasting > 48 hours; however, no significant differences were found between the subgroups. There is no consensus in literature on whether the form of paroxysmal or persistent arrhythmia is associated with a greater severity of depressive disorders [40-41]. However, there was a reduction in the severity of depressive disorders in the population with effective ablation of atrial fibrillation [42]. In the AF patient population a significant influence of depressive and anxiety disorders on the quality of life [43] and a higher sense of AF symptoms [14] were also confirmed. It seems that elevated values of depression parameters result mainly from questions about the somatic dimension of depression [37]. What is more, it is suggested that higher results in scales measuring the severity of depressive and anxiety disorders are also related to the subjectively higher perception of atrial fibrillation symptoms [14]. Based on the analysis of 34 publications describing the coexistence of atrial fibrillation and depressive and anxiety disorders, Patel et al. postulate the existence of complex relationships between these disease states [44]. On the one hand, the occurrence of atrial fibrillation may cause an increase in depression and anxiety symptoms. On the other hand, severe depressive or anxiety disorders create a favourable state for the occurrence or persistence of arrhythmias. Another important issue is the serious impact of mental disorders on experiencing the disease and feeling its symptoms. Effective actions lowering the perception of depressive and anxiety symptoms may result in increased effectiveness of anti-arrhythmic therapeutic activities. For many years, scientific works devoted to depressive disorders indicate their extensive impact on cognitive functioning [45-46]. What is more, it is believed that cognitive impairment is an important component of the clinical picture of depressive disorders and may affect many dimensions, such as memory, attention, concentration, and executive functions [47]. Two main aspects of cognitive impairment are observed in patients with depression. The first of these is the observed psychomotor slowing, giving worse results in many neuropsychological tests [51]. The second is the symptoms of hypofrontality, i.e. the deterioration of prefrontal cortex function, manifesting as functional memory dysfunctions and executive functions [48-50]. In the present study, the analysis of BDI result correlation showed their significant positive relationship with the results of prefrontal tests (TMT B, Stroop 1 and 2), but also for delayed memory in RAVLT A6 and A7 trials (Table 6).

For many years, studies on depressive disorders have indicated their extensive impact on cognitive functioning [45-46]. What is more, it is believed that cognitive impairment is an important component of the clinical image of depressive disorders and may affect many dimensions, such as memory, attention, concentration, and executive functions [47].

Two main aspects of cognitive impairment are observed in patients with depression. The first of these is the observed psychomotor slowing, leading to worse results in many neuropsychological tests [51]. The second is the symptoms of hypofrontality, i.e. the deterioration of prefrontal cortex function, manifesting as functional memory dysfunctions and executive functions $[48,49,50]$. In the present study, the analysis of BDI result correlation showed their significant positive relationship with the results of prefrontal tests (TMT $B$, Stroop 1 and 2), but also for delayed memory in RAVLT A6 and A7 trials (Table 6). Nevertheless, more accurate investigations revealed that this significance is true only in the subgroup of people with AF $<48$ hours, despite slightly lower BDI median scores among these patients. It seems, however, that based on these data, one cannot formulate conclusions about the existence of associations of depressive disorders and cognitive dysfunctions in this group of patients before determining the links between AF and cognitive impairment in multicentre studies. 


\section{Conclusions}

The permanent type of atrial fibrillation was associated with worse psychophysical performance indicators in the form of less exercise capacity, greater left atrium size in echocardiography, retarded memory impairment, and inferior attention processes, visual search, mental work rate, and executive functions (ability to control the course activities). More than half of patients with atrial fibrillation presented features of depressive disorders, which was more frequent than in general population reports.

\section{Limitations}

The lack of neuroimaging should be taken as a limitation of the work, which could have revealed the morphological effects of the previously medically silent episodes of central nervous system ischaemia and shown possible changes in the morphology relevant to the analysis of brain regions. In the criteria, however, the qualifying study was based on anamnesis and lack of brain incidents. Also, a small study group does not allow for strong conclusions.

\section{References}

1. Camm AJ, Lip GYH, De Caterina R, et al. ESC Committee for Practice Guidelines (CPG). 2012 focused update of the ESC Guidelines for the management of atrial fibrillation: an update of the 2010 ESC Guidelines for the management of atrial fibrillation. Developed with the special contribution of the European Heart Rhythm Association. Eur Heart J. 2012; 33(21): 2719-2747, doi: 10.1093/eurheartj/ehs253, indexed in Pubmed: 22922413.

2. Chugh SS, Havmoeller R, Narayanan $K$, et al. Worldwide epidemiology of atrial fibrillation: a Global Burden of Disease 2010 Study. Circulation. 2014; 129(8): 837-847, doi: 10.1161/CIRCULATIONAHA.113.005119, indexed in Pubmed: 24345399.

3. Nguyen TuN, Hilmer SN, Cumming RG. Review of epidemiology and management of atrial fibrillation in developing countries. Int J Cardiol. 2013; 167(6): 2412-2420, doi: 10.1016/j.ijcard.2013.01.184, indexed in Pubmed: 23453870.

4. Schnabel RB, Yin X, Gona P, et al. 50 year trends in atrial fibrillation prevalence, incidence, risk factors, and mortality in the Framingham Heart Study: a cohort study. Lancet. 2015; 386(9989): 154-162, doi: 10.1016/S0140-6736(14)61774-8, indexed in Pubmed: 25960110.

5. Frankel G, Kamrul R, Kosar L, et al. Rate versus rhythm control in atrial fibrillation. Can Fam Physician. 2013; 59(2): 161-168, indexed in Pubmed: 23418244.

6. Quu C, von Strauss E, Fastbom J, et al. Low blood pressure and risk of dementia in the Kungsholmen project: a 6-year follow-up study. Arch Neurol. 2003; 60(2): 223-228, indexed in Pubmed: 12580707.

7. Ihara M, Washida K. Linking Atrial Fibrillation with Alzheimer's Disease Epidemiological, Pathological, and Mechanistic Evidence. J Alzheimers Dis. 2018; 62(1): 61-72, doi: 10.3233/JAD-170970, indexed in Pubmed: 29439352.

8. Duschek S, Meinhardt J, Schandry R. Reduced cortical activity due to chronic low blood pressure: an EEG study. Biol Psychol. 2006; 72(3): 241-250, doi: 10.1016/j.biopsycho.2005.06.011, indexed in Pubmed: 16460867.

9. O'Connell JE, Gray CS, French JM, et al. Atrial fibrillation and cognitive function: case-control study. J Neurol Neurosurg Psychiatry. 1998: 65(3): 386-389, indexed in Pubmed: 9728958.

10. Senoo K, Kondo Y, Kobayashi Y, et al. Silent Cerebral Infarction in East Asian vs. Non-Asian Atrial Fibrillation Patients - Meta-Analysis. Circ
J. 2018; 82(3): 672-676, doi: 10.1253/circj.CJ-17-1164, indexed in Pubmed: 29279460

11. Rivard L, Khairy P. Mechanisms, Clinical Significance, and Prevention of Cognitive Impairment in Patients With Atrial Fibrillation. Can J Cardiol. 2017; 33(12): 1556-1564, doi: 10.1016/j.cjca.2017.09.024, indexed in Pubmed: 29173598.

12. Kupper N, van den Broek KC, Widdershoven J, et al. Subjectively reported symptoms in patients with persistent atrial fibrillation and emotional distress. Front Psychol. 2013; 4: 192, doi: 10.3389/fpsyg.2013.00192, indexed in Pubmed: 23630509.

13. Schnabel RB, Michal $M$, Wilde $S$, et al. Depression in atrial fibrillation in the general population. PLoS One. 2013; 8(12): e79109, doi: 10.1371/journal.pone.0079109, indexed in Pubmed: 24324579.

14. Thompson TS, Barksdale DJ, Sears SF, et al. The effect of anxiety and depression on symptoms attributed to atrial fibrillation. Pacing Clin Electrophysiol. 2014; 37(4): 439-446, doi: 10.1111/pace.12292, indexed in Pubmed: 24215267

15. Udompanich S, Lip GYH, Apostolakis S, et al. Atrial fibrillation as a risk factor for cognitive impairment: a semi-systematic review. QJM. 2013; 106(9): 795-802, doi: 10.1093/qjmed/hct129, indexed in Pubmed: 23737509

16. Thacker EL, McKnight B, Psaty BM, et al. Atrial fibrillation and cognitive decline: a longitudinal cohort study. Neurology. 2013; 81(2) 119-125, doi: 10.1212/WNL.0b013e31829a33d1, indexed in Pubmed: 23739229

17. Gaita F, Corsinovi L, Anselmino M, et al. Prevalence of silent cerebral ischemia in paroxysmal and persistent atrial fibrillation and correlation with cognitive function. J Am Coll Cardiol. 2013; 62(21): 1990-1997, doi: 10.1016/j.jacc.2013.05.074, indexed in Pubmed: 23850917.

18. Elshazly MB, Senn T, Wu Y, et al. Impact of Atrial Fibrillation on Exercise Capacity and Mortality in Heart Failure With Preserved Ejection Fraction: Insights From Cardiopulmonary Stress Testing. J Am Heart Assoc. 2017; 6(11), doi: 10.1161/JAHA.117.006662, indexed in Pubmed: 29089343.

19. Mead GE, Flapan AD, Elder AT. Electrical cardioversion for atrial fibrillation and flutter. Cochrane Database Syst Rev. 2002(1): CD002903, doi: 10.1002/14651858.CD002903, indexed in Pubmed: 11869642.

20. Atwood JE, Myers J, Sullivan M, et al. The effect of cardioversion on maximal exercise capacity in patients with chronic atrial fibrillation. Am Heart J. 1989; 118(5 Pt 1): 913-918, indexed in Pubmed: 2816702.

21. Lundström $T$, Karlsson $O$. Improved ventilatory response to exercise after cardioversion of chronic atrial fibrillation to sinus rhythm. Chest. 1992; 102(4): 1017-1022, indexed in Pubmed: 1395736.

22. Lee SP, Kim YJ, Lee JM, et al. Association of heart rhythm with exercise capacity after operation for chronic mitral regurgitation. Ann Thorac Surg. 2012; 93(6): 1888-1895, doi: 10.1016/j.athoracsur.2012.01.113, indexed in Pubmed: 22537534.

23. Smith PJ, Blumenthal JA, Hoffman BM, et al. Aerobic exercise and neurocognitive performance: a meta-analytic review of randomized controlled trials. Psychosom Med. 2010; 72(3): 239-252, doi: 10.1097/PSY.0b013e3181d14633, indexed in Pubmed: 20223924.

24. Borkowska A, Rybakowski JK. Does risperidone act better in schizophrenic patients who have a family or obstetric history? Prog Neuropsychopharmacol Biol Psychiatry. 2002; 26(7-8): 1349-1353, indexed in Pubmed: 12502024

25. Bollaert RE, Motl RW. Physical and Cognitive Functions, Physical Activity, and Sedentary Behavior in Older Adults With Multiple Sclerosis. J Geriatr Phys Ther. 2017 [Epub ahead of print], doi: 10.1519/JPT.0000000000000163, indexed in Pubmed: 29200085.

26. Frith E, Loprinzi PD. Physical activity is associated with higher cognitive function among adults at risk for Alzheimer's disease. Complement Ther Med. 2018; 36: 46-49, doi: 10.1016/j.ctim.2017.11.014, indexed in Pubmed: 29458929

27. Hamer M, Muniz Terrera G, Demakakos P. Physical activity and trajectories in cognitive function: English Longitudinal Study of Ageing. J Epidemiol Community Health. 2018 [Epub ahead of print], doi: 10.1136/jech-2017-210228, indexed in Pubmed: 29434025.

28. Meyer A, Günther S, Volmer T, et al. A 12-month, moderate-intensity exercise training program improves fitness and quality of life in adults with asthma: a controlled trial. BMC Pulm Med. 2015; 15: 56, doi: 10.1186/s12890-015-0053-8, indexed in Pubmed: 25947010.

29. Saulicz M, Saulicz E, Myśliwiec A, et al. Effect of a 4-week Nordic walking training on the physical fitness and self-assessment of the quality of health of women of the perimenopausal age. Prz Menopauzalny. 2015; 14(2): 105-111, doi: 10.5114/pm.2015.52152, indexed in Pubmed: 26327897

30. Smolis-Bąk E, Dąbrowski R, Piotrowicz E, et al. Hospital-based and telemonitoring guided home-based training programs: effects on exercise tolerance and quality of life in patients with heart failure (NYHA 
class (II) and cardiac resynchronization therapy. A randomized, prospective observation. Int J Cardiol. 2015; 199: 442-447, doi: 10.1016/i. ijcard.2015.07.041, indexed in Pubmed: 26276068

31. Roma I, de Almeida ML, Mansano Nd, et al. [Quality of life in adults and elderly patients with rheumatoid arthritis]. Rev Bras Reumatol. 2014; 54(4): 279-286, doi: 10.1016/j.rbr.2014.03.025, indexed in Pubmed: 25627223.

32. Batcho CS, Stoquart G, Thonnard JL. Brisk walking can promote functional recovery in chronic stroke patients. J Rehabil Med. 2013; 45(9) 854-859, doi: 10.2340/16501977-1211, indexed in Pubmed: 23974944

33. Barriga S, Rodrigues F, Bárbara C. Factors that influence physical activity in the daily life of male patients with chronic obstructive pulmonary disease. Rev Port Pneumol. 2014; 20(3): 131-137, doi: 10.1016/j. rppneu.2013.09.004, indexed in Pubmed: 24418722.

34. Freitas PD, Silva AG, Ferreira PG, et al. Exercise Improves Physical Activity and Comorbidities in Obese Adults with Asthma. Med Sci Sports Exerc. 2018 [Epub ahead of print], doi: 10.1249/MSS.0000000000001574, indexed in Pubmed: 29432326.

35. Kiejna A, Piotrowski P, Adamowski T, et al. [The prevalence of common mental disorders in the population of adult Poles by sex and age structure - an EZOP Poland study]. Psychiatr Pol. 2015; 49(1): 15-27, doi: 10.12740/PP/30811, indexed in Pubmed: 25844407.

36. Kupper N, van den Broek KC, Widdershoven J, et al. Subjectively reported symptoms in patients with persistent atrial fibrillation and emotional distress. Front Psychol. 2013; 4: 192, doi: 10.3389/fpsyg.2013.00192, indexed in Pubmed: 23630509.

37. Schnabel RB, Michal M, Wilde S, et al. Depression in atrial fibrillation in the general population. PLoS One. 2013; 8(12): e79109, doi 10.1371/journal.pone.0079109, indexed in Pubmed: 24324579.

38. Lioni L, Vlachos K, Letsas KP, et al. Differences in quality of life, anxiety and depression in patients with paroxysmal atrial fibrillation and common forms of atrioventricular reentry supraventricular tachycardias. Indian Pacing Electrophysiol J. 2014; 14(5): 250-257, indexed in Pubmed: 25408565

39. Ariansen I, Dammen T, Abdelnoor M, et al. Mental health and sleep in permanent atrial fibrillation patients from the general population Clin Cardiol. 2011: 34(5): 327-331, doi: 10.1002/clc.20883, indexed in Pubmed: 21319172

40. von Eisenhart Rothe AF, Goette A, Kirchhof P, et al. Depression in paroxysmal and persistent atrial fibrillation patients: a cross-sectiona comparison of patients enroled in two large clinical trials. Europace. 2014; 16(6): 812-819, doi: 10.1093/europace/eut361, indexed in Pubmed: 24351885
41. Dabrowski R, Smolis-Bak E, Kowalik I, et al. Quality of life and depression in patients with different patterns of atrial fibrillation. Kardiol Pol. 2010; 68(10): 1133-1139, indexed in Pubmed: 20967710.

42. Efremidis M, Letsas KP, Lioni L, et al. Association of quality of life, anxiety, and depression with left atrial ablation outcomes. Pacing Clin Electrophysiol. 2014; 37(6): 703-711, doi: 10.1111/pace.12420, indexed in Pubmed: 24809737.

43. Akintade BF Chapa D, Friedmann E et al. The influence of depression and anxiety symptoms on health-related quality of life in patients with atrial fibrillation and atrial flutter. J Cardiovasc Nurs. 2015; 30(1): 66-73, doi: 10 1097/JCN 0000000000000107 , indexed in Pubmed: 24165697.

44. Patel D, Mc Conkey ND, Sohaney R, et al. A systematic review of depression and anxiety in patients with atrial fibrillation: the mind-heart link. Cardiovasc Psychiatry Neurol. 2013; 2013: 159850, doi: 10.1155/2013/159850, indexed in Pubmed: 23710335.

45. Zakzanis KK, Leach L, Kaplan E. On the nature and pattern of neurocognitive function in major depressive disorder. Neuropsychiatry Neuropsychol Behav Neurol. 1998; 11(3): 111-119, indexed in Pubmed: 9742509

46. Ottowitz WE, Dougherty DD, Savage CR. The neural network basis for abnormalities of attention and executive function in major depressive disorder: implications for application of the medical disease model to psychiatric disorders. Harv Rev Psychiatry. 2002; 10(2): 86-99, indexed in Pubmed: 11897749.

47. Sheline YI, Barch DM, Garcia K, et al. Cognitive function in late life depression: relationships to depression severity, cerebrovascular risk factors and processing speed. Biol Psychiatry. 2006; 60(1): 58-65, doi: 10.1016/j.biopsych.2005.09.019, indexed in Pubmed: 16414031.

48. Borkowska A, Rybakowski JK. Neuropsychological frontal lobe tests indicate that bipolar depressed patients are more impaired than unipoar. Bipolar Disord. 2001 : 3(2): 88-94 indexed in Pubmed: 11333068.

49. Borkowska A, Drozdz W, Jurkowski P, et al. The Wisconsin Card Sorting Test and the $\mathrm{N}$-back test in mild cognitive impairment and elderly depression. World J Biol Psychiatry. 2009; 10(4 Pt 3): 870-876, doi: 10.1080/15622970701557985, indexed in Pubmed: 17853256.

50. Martínez-Arán A, Vieta E, Colom F, et al. Cognitive dysfunctions in bipolar disorder: evidence of neuropsychological disturbances. Psychother Psychosom. 2000; 69(1): 2-18, doi: 10.1159/000012361, indexed in Pubmed: 10601830

51. Pardo JV Pardo PJ, Humes SW et al Neurocognitive dysfunction in antidepressant-free, non-elderly patients with unipolar depression: alerting and covert orienting of visuospatial attention. J Affect Disord. 2006; 92(1): 71-78, doi: 10.1016/j.jad.2005.12.037, indexed in Pubmed: 16458363. 